University of South Carolina

Scholar Commons

$1-1-2008$

\title{
Acceptor Levels in GaSe:In Crystals Investigated by Deep-Level Transient Spectroscopy and Photoluminescence
}

\author{
Y. Cui \\ R. Dupere \\ A. Burger \\ D. Johnstone \\ K. C. Mandal \\ University of South Carolina - Columbia, mandalk@engr.sc.edu
}

See next page for additional authors

Follow this and additional works at: https://scholarcommons.sc.edu/elct_facpub

Part of the Electrical and Electronics Commons

\section{Publication Info}

Published in Journal of Applied Physics, Volume 103, Issue 1, 2008, pages 013710-1-013710-4.

(C) Journal of Applied Physics 2008, American Institute of Physics

Cui, Y., Dupere, R., Burger, A., Johnstone, D., Mandal, K. C., \& Payne, S. A. (1 January 2008). Acceptor levels in GaSe:In crystals investigated by deep-level transient spectroscopy and photoluminescence. Journal of Applied Physics, 103(1), \#013710. http://dx.doi.org/10.1063/1.2831130

http://scitation.aip.org/content/aip/journal/jap/103/1/10.1063/1.2831130

This Article is brought to you by the Electrical Engineering, Department of at Scholar Commons. It has been accepted for inclusion in Faculty Publications by an authorized administrator of Scholar Commons. For more information, please contact digres@mailbox.sc.edu. 


\section{Author(s)}

Y. Cui, R. Dupere, A. Burger, D. Johnstone, K. C. Mandal, and S. A. Payne 


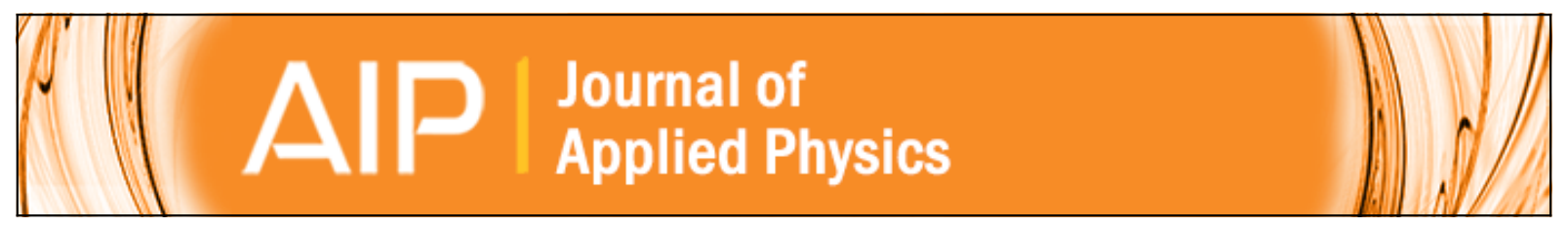

\section{Acceptor levels in GaSe:In crystals investigated by deep-level transient spectroscopy and photoluminescence}

Yunlong Cui, Ryan Dupere, Arnold Burger, D. Johnstone, Krishna C. Mandal, and S. A. Payne

Citation: Journal of Applied Physics 103, 013710 (2008); doi: 10.1063/1.2831130

View online: http://dx.doi.org/10.1063/1.2831130

View Table of Contents: http://scitation.aip.org/content/aip/journal/jap/103/1?ver=pdfcov

Published by the AIP Publishing

\section{Articles you may be interested in}

Deep levels in GaTe and GaTe:In crystals investigated by deep-level transient spectroscopy and photoluminescence

J. Appl. Phys. 105, 053709 (2009); 10.1063/1.3080157

Deep-level transient spectroscopy of TiO 2/CulnS 2 heterojunctions

Appl. Phys. Lett. 87, 242103 (2005); 10.1063/1.2140611

Current deep-level transient spectroscopy investigation of acceptor levels in Mg-doped GaN

Appl. Phys. Lett. 79, 1631 (2001); 10.1063/1.1401779

Photoluminescence of undoped and neutron-transmutation-doped InSe

J. Appl. Phys. 88, 4654 (2000); 10.1063/1.1308066

Optically and thermally detected deep levels in n-type Schottky and p + -n GaN diodes

Appl. Phys. Lett. 76, 3064 (2000); 10.1063/1.126580

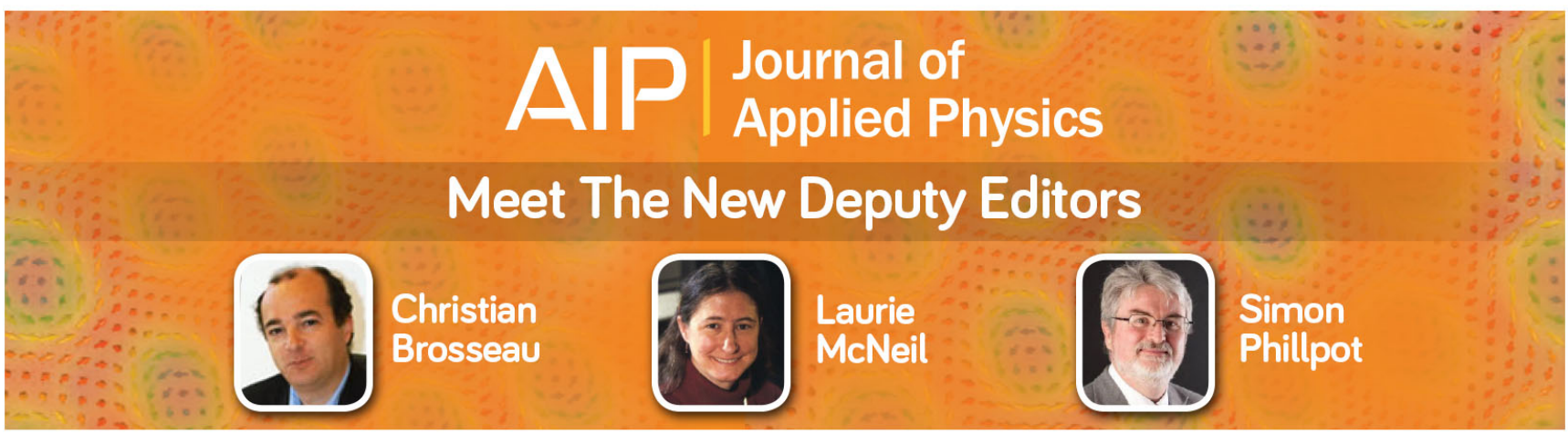




\title{
Acceptor levels in GaSe:In crystals investigated by deep-level transient spectroscopy and photoluminescence
}

\author{
Yunlong Cui, ${ }^{\text {a) }}$ Ryan Dupere, and Arnold Burger \\ Physics Department, Fisk University, Nashville, Tennessee 37208, USA \\ D. Johnstone \\ SEMETROL, 13312 Shore Lake Turn, Chesterfield, Virginia 23838, USA
}

Krishna C. Mandal

EIC Laboratories, Inc., 111 Downey Street, Norwood, Massachusetts 02062, USA

\author{
S. A. Payne \\ Lawrence Livermore National Laboratory, Livermore, California 94550, USA
}

(Received 20 September 2007; accepted 10 November 2007; published online 15 January 2008)

\begin{abstract}
Deep-acceptor levels associated with indium in indium-doped GaSe crystals have been measured. High-quality Schottky diodes of GaSe:In have been fabricated and characterized using current-voltage, capacitance-voltage, and deep-level transient spectroscopy (DLTS). Four DLTS peaks at $127,160,248$, and $319 \mathrm{~K}$, corresponding to $0.21,0.22,0.44$, and $0.74 \mathrm{eV}$ above the valence band, were well resolved and assigned to be an indium-on-gallium antisite $\left(\operatorname{In}_{\mathrm{Ga}}\right)$, a gallium vacancy $\left(V_{\mathrm{Ga}}\right)$, an indium gallium vacancy complex $\left(V_{\mathrm{Ga}}-\mathrm{In}\right)$, and a native defect associated with stacking fault or dislocation, respectively. Low-temperature photoluminescence (PL) spectroscopy measurements were performed on GaSe and GaSe:In crystals. The ground and the first excited states of the free exciton emissions were identified and the band-gap energies were determined. The results that the peak of exciton bound to acceptor $\left(A^{0}, X\right)$ disappeared and the peak of donor-acceptor pair appeared in GaSe crystal after indium doping are consistent with the DLTS acceptor assignments.
\end{abstract}

(C) 2008 American Institute of Physics. [DOI: 10.1063/1.2831130]

\section{INTRODUCTION}

Gallium selenide ( $\mathrm{GaSe}$ ) has been studied for decades as a layered structure nonlinear optical material. ${ }^{1}$ Recently, it has become a material of choice for terahertz wave generation and detection. ${ }^{2-4}$ The electrical and optical properties of GaSe doped with different elements could differ significantly compared to the properties of unintentionally doped GaSe. The identification of the donor and acceptor levels between the valence and conduction bands of GaSe is important in view of its further applications in photoelectronic devices, such as room temperature radiation detectors. ${ }^{5}$

GaSe:In, GaSe doped with indium, is a promising semiconductor compound. It is well known that the mechanical softness of GaSe is the main flaw that limits GaSe applications. However, the microhardness of GaSe crystals can be improved noticeably after doping them with indium. ${ }^{6,7}$ Not only the second harmonic generation efficiency, but also the hole mobility of GaSe:In as compared with GaSe have been improved. The highest hole mobility of GaSe:In at $300 \mathrm{~K}$ has been reported to be $1.08 \times 10^{3} \mathrm{~cm}^{2} / \mathrm{V} \mathrm{s}$ (see Table 2 in Ref. 6). The value is high enough to make GaSe:In potential candidates for room temperature radiation detectors although the dependences of hole mobility on temperature and indium concentration need further investigation to clarify the mechanism of hole scattering by the dopants and phonons. ${ }^{8}$ The carrier mobility-lifetime product is an important figure of merit in the evaluation of x-ray and gamma-ray semiconduc-

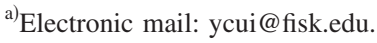

tor detectors; the carrier lifetime is determined by the trap concentrations and the capture cross sections.

Deep-level transient spectroscopy (DLTS) and lowtemperature photoluminescence (PL) techniques are two sensitive techniques to identify defects. Acceptor levels in undoped $p$-GaSe (Ref. 9) and GaSe doped with elements, such as $\mathrm{Sn},{ }^{8} \mathrm{Cd},{ }^{10} \mathrm{Mn},{ }^{11,12} \mathrm{Cu},{ }^{13,14} \mathrm{Er},{ }^{15} \mathrm{~N},{ }^{16}$ and $\mathrm{Co},{ }^{17}$ have been investigated. However, to our knowledge, the acceptors levels of GaSe:In have not been yet reported. In this article, we have studied the acceptor levels of GaSe:In employing DLTS and PL techniques. Four well resolved acceptor levels have been observed in the DLTS spectrum, two of them associated with indium. The PL measurements are consistent with the DLTS assignments.

\section{EXPERIMENT}

GaSe crystals and GaSe:In crystals doped with 1000 ppm indium were grown in the EIC lab by the temperature gradient solution growth method. The typical size of a GaSe:In sample is $7.0 \times 5.0 \times 0.5 \mathrm{~mm}^{3}$. For DLTS measurements, samples were cleaned in acetone using an ultrasonic bath. After drying in the air, they were cleaved and Au metal spots with diameter of $1.1 \mathrm{~mm}$ were sputtered using $50 \mathrm{~W}$ radio frequency power on the fresh surfaces to create Schottky contacts; ${ }^{18}$ high purity indium were then soldered to the other surfaces to form Ohmic contacts. The crystallographic $c$ axis is perpendicular to the contact surfaces [(001) plane]. 


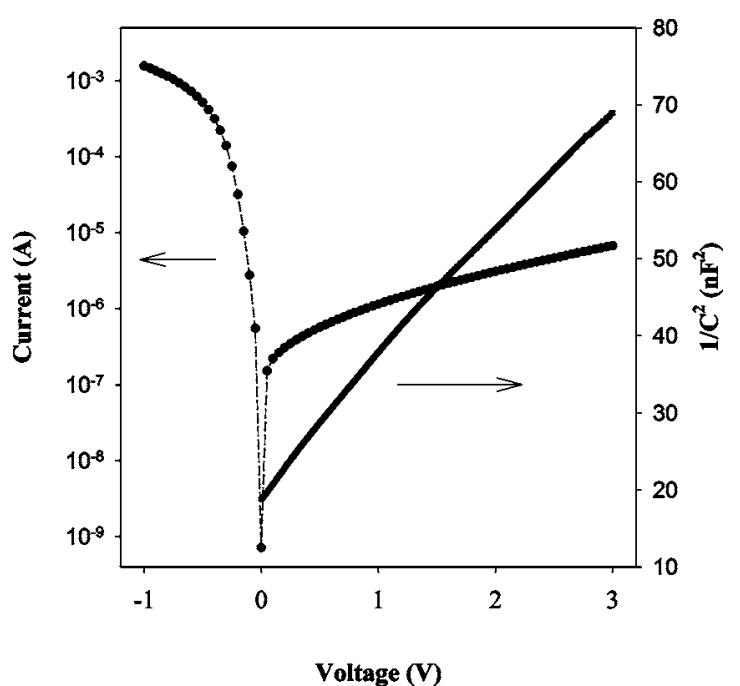

FIG. 1. The $I-V$ curve (left) and the plot of $1 / C^{2}$ vs voltage (right) for GaSe:In Schottky diode measured at room temperature. The In contact was grounded. The diameter of the Au contact was $1.1 \mathrm{~mm}$.

Current-voltage, capacitance-voltage, and DLTS measurements were carried out on the Schottky diodes to analyze their characteristics. The fully automated LABVIEW controlled DLTS system was designed by SEMETROL. DLTS capacitance was measured at $1 \mathrm{MHz}$ using a Boonton 7200 capacitance meter. A SiC sample was used as a standard. The temperature deviation tolerance at each temperature point was less than $1 \mathrm{~K}$.

For the low-temperature PL measurements, the samples were cooled down to about $9 \mathrm{~K}$ using an APD Cryogenic Inc. dual HC-4MK I helium compressors. The crystals were illuminated with the $488 \mathrm{~nm}$ line of an ILT 5500A air-cooled argon-ion laser with density of $2.0 \mathrm{~W} / \mathrm{cm}^{2}$. The photoluminescence spectra were detected using a SPEX 1877D Triplemate spectrometer in conjunction with a liquid nitrogen cooled charge coupled device (CCD) detector. A $0.1 \mathrm{~mm}$ slit and a grating with 300 grooves $/ \mathrm{mm}$ were employed for the spectrometer. The spectral resolution was $1 \mathrm{~cm}^{-1}$.

\section{RESULTS AND DISCUSSION}

Figure 1 shows the current-voltage characteristics and the plot of $1 / C^{2}$ versus voltage for a GaSe:In Schottky diode measured at room temperature. The plot of $1 / C^{2}$ versus voltage deviates from a straight line when the applied bias is larger than $1.5 \mathrm{~V}$, which may indicate nonuniformity of indium doping. However, one can see that excellent rectification is obtained. The diode shows forward direction when a negative bias is applied to the Au contact, the ideality factor of the diode is 1.3. The formation of a high-quality Schottky diode is not only necessary for DLTS measurements, but also useful to make an electronic device such as roomtemperature radiation detector, since a low leakage current is achievable at a higher reverse bias. The GaSe:In sample is a $p$-type semiconductor material, the carrier (hole) concentration $N_{A}$ measured by $C-V$ is $1.5 \times 10^{16} / \mathrm{cm}^{3}$, and the built-in potential at room temperature is $-1.0 \mathrm{~V}$.

DLTS spectrum of GaSe:In is shown in Fig. 2. The filling pulse was $0 \mathrm{~V}$, the measurement bias was $1 \mathrm{~V}$, and the

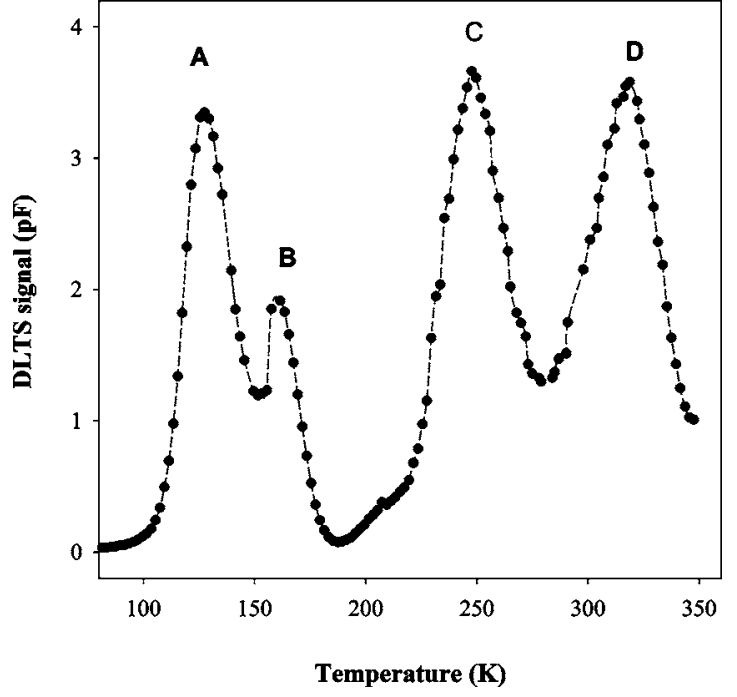

FIG. 2. DLTS spectrum of GaSe:In. The rate window was 29/s. The filling pulse was $0 \mathrm{~V}$, and the measurement bias was $1 \mathrm{~V}$.

rate window was $29 / \mathrm{s}$. The DLTS spectrum was generated from the difference in capacitance at two points during the emission transient as a function of temperature. ${ }^{19}$ The emission rate was extracted from a fit of the capacitance transient at each temperature as follows:

$$
C(t)=C_{0}+\Delta C \exp \left(-t e_{p}\right),
$$

where $C_{0}$ is the capacitance prior to the filling pulse, $\Delta C$ represents the difference between the capacitance at the beginning and at the end of the filling pulse, and $e_{p}$ is the hole emission rate. Four well-defined peaks, labeled as A, B, C, and $\mathrm{D}$, were observed. The peaks $\mathrm{B}$ and $\mathrm{D}$ have been reported in undoped $p$-GaSe single crystals using photoinduced current transient spectroscopy (PICTS). ${ }^{9}$ In the area of peak $\mathrm{C}$, a broad peak has been reported in GaSe samples doped with $\mathrm{Cd}, \mathrm{Mn}$, and $\mathrm{Cu},{ }^{10,11,13}$ and recently, two peaks close to peaks $\mathrm{C}$ and $\mathrm{D}$ have been found in a GaSe:Er sample. ${ }^{15}$

When the holes were emitted to the maximum of the valence band, the dependence of hole emission rate $e_{p}$ on the temperature was given as follows:

$$
e_{p}=\left(\sigma_{p} v_{p} N_{v}\right) \exp \left(-E_{t} / k T\right),
$$

where $\sigma_{p}$ is the hole capture cross section, $v_{p}$ the hole average thermal velocity, $N_{v}$ the density of states of the valence band, $E_{t}$ the thermal activation energy, $k$ the Boltzmann constant, and $T$ the peak temperature. If one assumes that $v_{p}$ varies as $T^{1 / 2}$ and $N_{v}$ as $T^{3 / 2}$, the activation energy and capture cross section of the trap levels can be determined from the slope and intercept of Arrhenius plot of $\ln \left(T^{2} / e_{p}\right)$ versus $1 / k T$. Furthermore, the concentration of a trap can be estimated from the peak height of the DLTS rate window spectrum as ${ }^{19}$

$$
N_{t}=2 N_{A}\left(\Delta C / C_{0}\right) .
$$

Figure 3 shows an Arrhenius plot for traps in GaSe:In. The trap energies capture cross sections, and assignments are listed in Table I. Since peaks B and D have been reported in the same temperature region for undoped $\mathrm{GaSe},{ }^{9}$ and the 


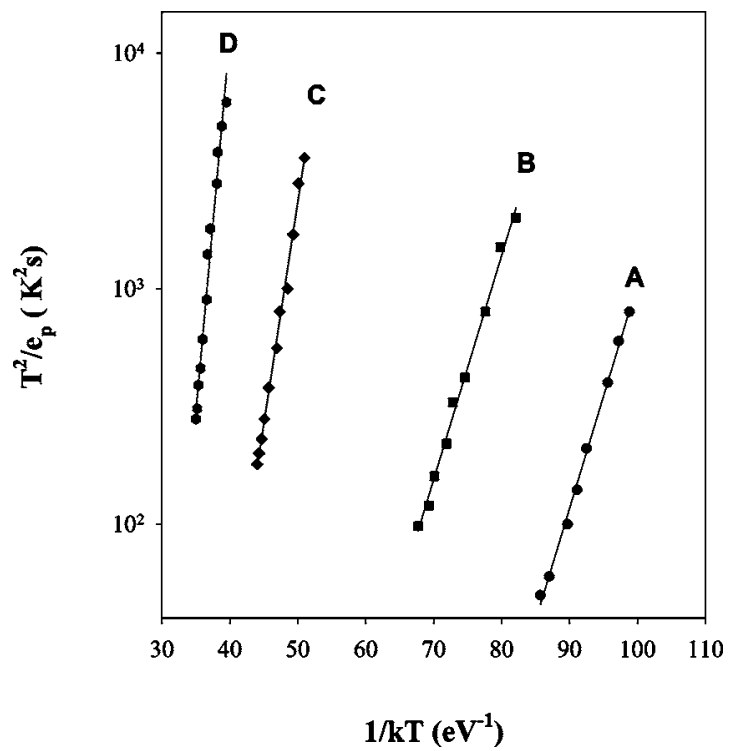

FIG. 3. Arrhenius plot for traps in GaSe:In. The trap energies capture cross sections, assignments and concentration are listed in Table I.

corresponding activation energy and capture cross section are comparable, it is reasonable to believe that peak B is due to a gallium vacancy and peak D to a stacking fault or dislocation, as suggested in Ref. 9. Peaks A and C were absent in undoped $\mathrm{GaSe}$, so they are attributed to defects associated with indium. At region of peak $\mathrm{C}$, a broad peak was observed in GaSe: $M(M=\mathrm{Cd}, \mathrm{Mn}, \mathrm{Cu}),{ }^{10,11,13}$ and its intensity was a function of the concentration of $M$; therefore, it was attributed to a defect complex associated with $M$. It should be emphasised that peak A has never been reported in doped GaSe. Indium and gallium belong to the same IIIA family and because the activation energies of the acceptor at peaks $\mathrm{A}$ and $\mathrm{B}$ are almost same, it is reasonable to believe that peak $\mathrm{A}$ is due to an occupation of a Ga vacancy with an indium atom, and formation of an antisite $\mathrm{In}_{\mathrm{Ga}}$. Peak $\mathrm{C}$ cannot associate with an indium interstitial $\mathrm{In}_{i}$, since like a gallium interstitial, the $\mathrm{In}_{i}$ may serve as a donor, instead of an acceptor. Therefore, we assign tentatively the acceptor at peak $\mathrm{C}$ to a $\mathrm{V}_{\mathrm{Ga}}$-In complex.

Low-temperature photoluminescence spectra of GaSe and GaSe:In crystals are shown in Fig. 4. The predominant peak in GaSe PL spectrum was attributed to the exciton bound to an acceptor $\left(A^{0}, X\right)$; the ground state free exciton $(X)_{n=1}$, one longitudinal optical phonon replica of the indirect free excitonic recombination (IFE), and the radiative recombination of indirect excitons bound to deep neutral acceptor center (IBE) were also identified. ${ }^{20}$ It is interesting to see that

TABLE I. The acceptor types, energies, capture cross sections, and concentrations determined by DLTS for the GaSe:In crystals.

\begin{tabular}{lllll}
\hline \hline Peak & Acceptor type & $\begin{array}{c}\text { Activation energy } \\
(\mathrm{eV})\end{array}$ & $\begin{array}{c}\text { Capture cross section } \\
\left(\mathrm{cm}^{2}\right)\end{array}$ & $\begin{array}{c}\text { Density } \\
\left(\mathrm{cm}^{-3}\right)\end{array}$ \\
\hline $\mathrm{A}$ & $\mathrm{In}_{\mathrm{Ga}}$ & 0.21 & $3.7 \times 10^{-15}$ & $3.0 \times 10^{15}$ \\
$\mathrm{~B}$ & $\mathrm{~V}_{\mathrm{Ga}}$ & 0.22 & $5.3 \times 10^{-17}$ & $1.2 \times 10^{15}$ \\
$\mathrm{C}$ & $\mathrm{V}_{\mathrm{Ga}}$-In & 0.44 & $2.2 \times 10^{-15}$ & $8.3 \times 10^{14}$ \\
$\mathrm{D}$ & Stacking fault & 0.74 & $1.1 \times 10^{-12}$ & $6.1 \times 10^{14}$ \\
\hline \hline
\end{tabular}

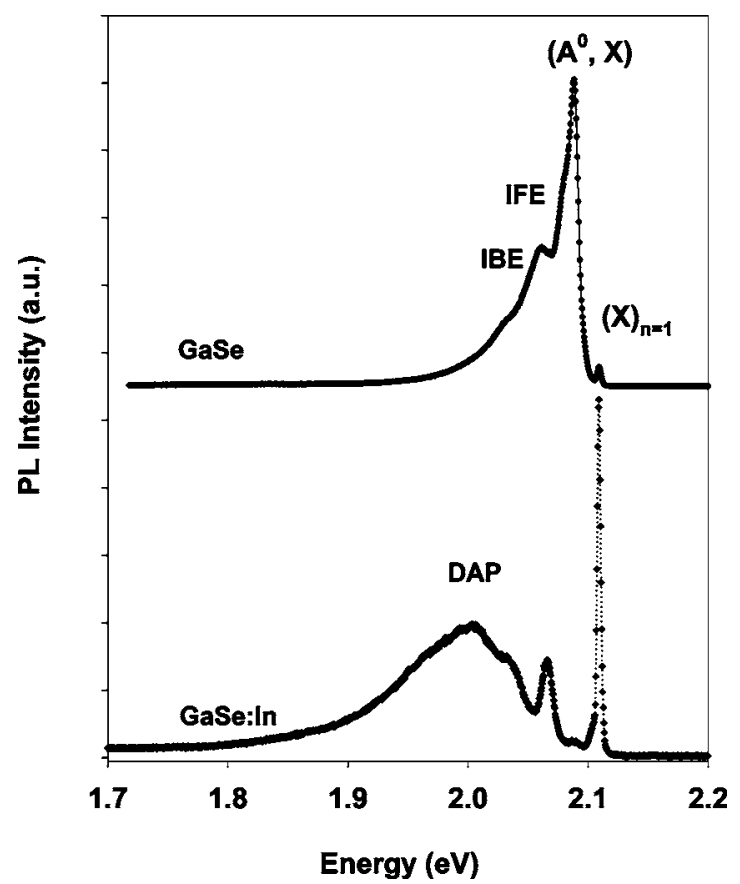

FIG. 4. Low-temperature (9 K) photoluminescence spectra of GaSe and GaSe:In crystals.

the $\left(A^{0}, X\right)$ peak almost disappears in GaSe:In, while a strong broad peak associated with indium appears. The broad peak is attributed to a donor-acceptor pair (DAP) transition mainly, and to a free electron bound to neutral acceptor transition partly. It is generally accepted that the major acceptors in undoped $\mathrm{GaSe}$ are gallium vacancies $V_{\mathrm{Ga}}$. Doped with indium, most of the gallium vacancies are occupied by indium atoms, and the $\mathrm{In}_{\mathrm{Ga}}$ defects may be nonradative centers. Therefore, the $\left(A^{0}, X\right)$ peak of GaSe:In decreases significantly while the $(X)_{n=1}$ peak becomes dominate compared with those of GaSe. It is worth noting that the acceptor level $\mathrm{C}$ observed by DLTS is deeper than that measured from DAP.

The GaSe and GaSe:In samples used in the research have a high level of crystallinity. Except the ground-state free excitons observed in GaSe and GaSe:In crystals at temperatures varied from 9 to $300 \mathrm{~K}$, first-excited-state free excitons $(X)_{n=2}$ in GaSe crystal were successfully observed in the temperature range of $20-100 \mathrm{~K}$. Figure 5 shows temperature dependence of the free exciton peak energies of GaSe and GaSe:In crystals. From the position of $(X)_{n=1}$ and $(X)_{n=2}$, one can determine the exciton binding energy (Rydberg energy $R$ ) and the band-gap energies at different temperatures, $E_{g}(T)$, using the relation

$$
E_{n}(T)=E_{g}(T)-R / n^{2},
$$

where $E_{n}(T)$ is the peak position of the $n$th free exciton. The value of $R$ is obtained as $18.6 \mathrm{meV}$ at $20 \mathrm{~K}$. One can see that the band gaps of undoped GaSe and GaSe doped with $1000 \mathrm{ppm}$ indium are almost the same.

In summary, we have fabricated high-quality Schottky diodes and identified new acceptor levels associated with indium by deep-level transient spectroscopy. The assignments of new acceptor levels are consistent with the low- 


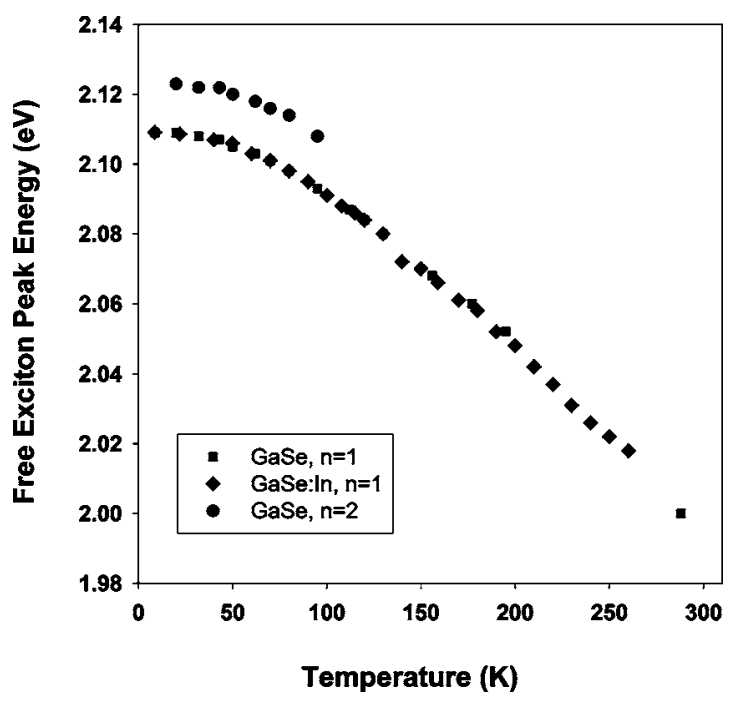

FIG. 5. Temperature dependences of free exciton peak energies of GaSe and GaSe:In crystals.

temperature photoluminescence results. The identification of new acceptor levels and the fabrication of Schottky diodes will be helpful to the development of electronic device based on GaSe:In crystals.

\section{ACKNOWLEDGMENTS}

The authors acknowledge partial financial support provided by the DHS/DNDO under Contract No. HSHQDC-07C-00034. The authors at Fisk University gratefully acknowledge financial support from the NSF-supported Center of
Research Excellence in Science and Technology (CREST, Cooperative Agreement CA-0420516). The authors would also like to thank Dr. Silberman for his valuable suggestions and Mr. V. Buliga for helping prepare the metal contacts.

${ }^{1}$ For a review of the GaSe literature, see, for example, N. C. Fernelius, Prog. Cryst. Growth Charact. Mater. 28, 275 (1994).

${ }^{2}$ W. Shi, Y. Ding, N. Fernelius, and K. Vodopyanov, Opt. Lett. 27, 1454 (2002).

${ }^{3}$ K. Liu, J. Xu, and X.-C. Zhang, Appl. Phys. Lett. 85, 863 (2004).

${ }^{4}$ B. L. Yu, F. Zeng, V. Kartazayev, R. R. Alfano, and K. C. Mandal, Appl. Phys. Lett. 87, 182104 (2005).

${ }^{5}$ See, for example, G. F. Knoll, Radiation Detection and Measurement, 3rd ed. (Wiley, New York, 1999).

${ }^{6}$ V. G. Voevodin, O. V. Voevodina, S. A. Bereznaya, Z. V. Korotchenko, A. N. Morozov, S. Y. Sarkisov, N. C. Fernelius, and J. T. Goldstein, Opt. Mater. (Amsterdam, Neth.) 26, 495 (2004).

${ }^{7}$ D. R. Suhre, N. B. Singh, V. Balakrishna, N. C. Fernelius, and F. K. Hopkins, Opt. Lett. 22, 775 (1997).

${ }^{8}$ J. F. Sanchez-Royo, D. Errandonea, A. Segura, L. Roa, and A. Chevy, J. Appl. Phys. 83, 4750 (1998).

${ }^{9}$ G. Micocci, P. Siciliano, and A. Tepore, J. Appl. Phys. 67, 6581 (1990).

${ }^{10}$ S. Shigetomi, T. Ikari, and H. Nakashima, J. Appl. Phys. 73, 4686 (1993).

${ }^{11}$ S. Shigetomi, T. Ikari, and H. Nakashima, J. Appl. Phys. 76, 310 (1994).

${ }^{12}$ S. Lee, S. Hann, C. Chung, S. Yun, and W. Kim, Solid State Commun. 60, 453 (1986)

${ }^{13}$ S. Shigetomi, T. Ikari, and H. Nakashima, J. Appl. Phys. 80, 4779 (1996).

${ }^{14}$ V. Capozzi and A. Minafra, J. Phys. C 14, 4335 (1981).

${ }^{15}$ Y. Hsu, C. Chang, and W. Huang, J. Appl. Phys. 96, 1563 (2004).

${ }^{16}$ J. F. Sanchez-Royo, A. Segura, A. Chevy, and L. Roa, J. Appl. Phys. 79, 204 (1996).

${ }^{17}$ C. Yoon, B. Lee, and W. Kim, Solid State Commun. 62, 583 (1987).

${ }^{18}$ See, for example, S. M. Sze, Physics of Semiconductor Device, 2nd ed. (Wiley, New York, 1981).

${ }^{19}$ D. V. Lang, J. Appl. Phys. 45, 3023 (1974).

${ }^{20}$ V. Capozzi and M. Montagna, Phys. Rev. B 40, 3182 (1989). 